Nau Literária: crítica e teoria de literaturas • seer.ufrgs.br/NauLiteraria
ISSN 1981-4526 • PPG-LET-UFRGS $\bullet$ Porto Alegre $\bullet$ vol. 09, n. 01 $\bullet$ jan/jun 2013
Dossiê: Voz e Interculturalidade

\title{
Um olhar sobre o legado das narrativas orais
}

\author{
Geice Peres Nunes ${ }^{1}$ \\ Carlos Nogueira (IELT -FSCH-UNL) ${ }^{2}$
}

\begin{abstract}
Resumo: Nosso estudo pretende mostrar que a herança deixada pelos Irmãos Grimm não se resume aos duzentos e dez contos de fadas publicados em Kinder- und Hausmärchen. A leitura de tais contos continua a seduzir gerações de leitores e de ouvintes. Somando-se a isso, permite ainda inúmeras adaptações no terreno da literatura, assim como no cinema, na televisão, na música, nas artes gráficas, dentre outras expressões artísticas e midiáticas. Nesse sentido, no presente estudo destacamos que o legado dos Grimm está, também, no método de recolha e de edição que eles definiram e divulgaram, bem como na dignidade e notoriedade que vieram trazer tanto às literaturas orais e populares como à literatura infanto-juvenil. No contato com os contos populares, podemos argumentar a existência de diferenças no modo como um "iletrado" e um "letrado" convivem com estes textos, mas isso não diminui em nada a importância quer desta literatura quer da recolha dos Irmãos Grimm. Na observação de tal convívio, percebemos a universalidade dos contos maravilhosos (e de outros gêneros orais), a sua transversalidade social e cultural; e se percebe como numa recolha de literatura oral não devemos ignorar determinadas classes sociais ou profissionais nem certas faixas etárias (nem as mais novas nem as intermédias). Nosso objetivo, portanto, assenta-se em mostrar como os contos dos Irmãos Grimm assumem uma herança antiga e são eles próprios uma herança deixada às gerações vindouras. Os contos representam um legado que continuará a desafiar-nos desde a simples palavra que o designa: "conto". Portanto, "popular", "oral", "tradicional", "folclórico", "de fadas" ou "maravilhoso" serão termos sempre insuficientes ou demasiado ambiciosos para catalogar os contos que nos colocamos a pensar.
\end{abstract}

Palavras-chave: Grimm; recolha; herança; folclore.

Resumen: Nuestro estudio pretende mostrar que la herencia dejada por los Hermanos Grimm no se resume a los doscientos diez cuentos de hadas publicados en Kinder- und Hausmärchen. La lectura de tales cuentos continúa a seducir generaciones de lectores y de oyentes. Además, permite aún inúmeras adaptaciones en el terreno de la literatura, así como en el cine, en la televisión, en la música, en las artes gráficas, entre otras expresiones artísticas y mediáticas. En ese sentido, en el presente estudio, destacamos que el legado de los Grimm está también en el método de colecta y de edición que los definieron y los divulgaron, así como en la dignidad y notoriedad que vinieron traer tanto a las

\footnotetext{
${ }^{1}$ Doutoranda em Letras - Estudos Literários (UFSM); Professora Substituta do Curso de Letras (UNIPAMPA Jaguarão).

${ }^{2}$ Professor Dr. Investigador IELT, Faculdade de Ciências Sociais e Humanas, FCSH, Universidade Nova de Lisboa, Lisboa - Portugal. Professor na Faculdade de Filologia e Tradução da Universidade de Vigo, Galiza, Espanha.
} 
literaturas orales y populares como a la literatura infantojuvenil. En el contacto con los cuentos populares, podemos argumentar la existencia de diferencias en el modo como un "iletrado" y un "letrado" conviven con estos textos, pero eso no disminuye en nada la importancia sea de esta literatura sea de la recoja de los Grimm. En la observación de tal convivio, percibimos la universalidad de los cuentos maravillosos (y de otros géneros orales), su transversalidad social y cultural; y se percibe como en una recoja de la literatura oral no debemos ignorar determinadas clases sociales o profesionales, ni ciertas edades (ni las más nuevas ni las intermedias). Nuestro objetivo, por lo tanto, se basa en mostrar como los cuentos de los Grimm asumen una herencia antigua y son ellos propios una herencia dejada a las generaciones siguientes. Los cuentos representan un legado que continuará a desafiarnos desde la simple palabra que lo designa: "cuento". Por lo tanto, "popular", "oral", "tradicional", "folclórico", "de hadas" o "maravilloso" serán términos siempre insuficientes o demasiado ambiciosos para catalogar los cuentos que nos ponemos a pensar.

Palabras-clave: Grimm; recoja; herencia; folclore.

Há muitos séculos que os contos maravilhosos vêm seduzindo ouvintes, assim como leitores de várias idades, desde que há versões impressas em folhetos de cordel e em livros. Também não é recente o interesse de filólogos e outros estudiosos por esta forma da literatura oral e, sobretudo desde finais do século XVII, da literatura para a infância e a juventude. A tradição escrita dos contos maravilhosos nasce da tradição dos contos orais. Outros, antes dos Irmãos Grimm, recolheram e publicaram contos da tradição oral (JOLLES, 1976, p. 181), mas foram Jacob (1785-1863) e Wilhelm Grimm (1786-1859) os primeiros a estabelecer um programa sistemático de recolha e de estudo. Fizeram-no com tal persistência e método que ainda hoje o seu modelo inicial permanece válido.

O trabalho dos Grimm teve, aliás, uma repercussão imediata em muitos países europeus, e por isso Jacob Grimm afirmava em 1860: "Tivemos a boa fortuna de encontrar esta varinha de condão e, desde que com ela tocamos no chão, por todo o lado se descobriu um tesouro rico em lendas e tradições" (GRIMM, 2012, p.14). Em Portugal, por exemplo, os primeiros resultados de vulto da tendência iniciada pelos Grimm surgiram com os Contos Populares Portugueses (1879), de Adolfo Coelho, e com os Contos Tradicionais do Povo Português (1883), de Teófilo Braga. Estas palavras de José Leite de Vasconcelos são uma espécie de síntese do impacto que a ação dos Grimm teve nos etnógrafos europeus:

Não falando de coletâneas de baladas e análogas poesias nacionais, feitos na Grã-Bretanha e Alemanha, dos últimos decênios do séc. XVII aos primeiros anos do XIX, e que podem considerar-se ensaios folclóricos, o estudo científico das tradições populares data verdadeiramente do tempo de dois famosos Eruditos alemães, Jacob e Wilhelm Grimm, irmãos um do outro, e que, ou de mútua colaboração, ou cada um em separado, deram a lume, de 1812 a 1835, obras valiosíssimas a respeito de contos, poesias, lendas, símbolos jurídicos, superstições e mitologia, as quais se tornaram exemplo e modelo de tudo quanto sobre o assunto veio após a publicar-se, na Europa, e fora, alargando-se a pouco e pouco a investigação, até atingir o grande e variado cultivo que hoje ostenta (VASCONCELOS, 1994, p. 232). 
As questões com que os Grimm se viram confrontados são essencialmente as mesmas que hoje se colocam aos colecionadores de literatura oral e aos estudiosos: de onde provêm os contos e como se difundem ${ }^{3}$, como (e onde) recolhê-los e transcrevê-los, como interpretá-los e divulgá-los, o que alterar ou cortar nas versões destinadas à infância. O conflito que existia entre a moral burguesa e o programa de fidelidade dos Grimm às fontes, no plano da obscenidade e crueza de episódios e da linguagem, persiste; e, sobretudo, continua a discussão à volta do que é próprio e impróprio para o leitor infantil e juvenil.

O debate entre Achim von Arnim e Jacob Grimm, a que temos acesso através da correspondência que os dois trocaram, a "Circular sobre a recolha de poesia popular" que Jacob "enviou em 1815 de Viena a quatro centenas de destinatários em toda a Alemanha" (BAIROS, 2012, p. 15) e o "Prefácio" de 1819 à segunda edição são bem indicativos das ideias e do trabalho dos Irmãos Grimm. Encontramos aqui uma teoria quer do conto popular quer da recolha de textos da literatura oral, que, em alguns aspectos, os Irmãos Grimm não puderam cumprir nem na primeira edição dos Kinder- und Hausmärchen, publicada em Berlim em 1812 (vol. I) e 1815 (vol. II), nem muito menos manter nas seis edições que se seguiram até a última edição em vida dos autores (1856-1857).

$\mathrm{Na}$ “Circular” de Jacob contém todo o programa dos Irmãos Grimm. Nela, propõe, em primeiro lugar, dentro do espírito romântico de valorização das tradições nacionais, recolher os textos da literatura oral, quer para salvaguardá-los do risco de perda irremediável, quer para os compreender através do estudo (e, desse modo, os dignificar):

\begin{abstract}
Caro senhor:
Formou-se uma sociedade que se expandirá por toda a Alemanha e que tem por objetivo salvaguardar e compilar tudo o que sejam canções e lendas do povo alemão. Na nossa pátria ainda abunda por todo o lado este tesouro que os nossos antepassados nos legaram. Apesar de todo o ridículo e troça de que tem sido alvo, ele sobreviveu em segredo, inconsciente da sua beleza e transportando a sua essência irreprimível. Se este tesouro não for estudado em pormenor, não se poderá compreender plenamente as origens autênticas e remotas da nossa poesia, da nossa história e da nossa língua (GRIMM, 2012, p. 15).
\end{abstract}

Mais à frente, depois de enumerar as espécies a compilar, Jacob expõe em pormenor o método de recolha que os seus eventuais colaboradores devem adotar, e nota, mais uma vez,

\footnotetext{
${ }^{3}$ Os Irmãos Grimm estabeleceram as fundações da teoria mitológica da origem dos contos, que, para eles, derivavam de mitos arianos. Jacob Grimm, ressentido com o desacordo de Arnim em relação às suas ideias, confessa que todo o seu projecto assenta nesta convicção: "O que tu dizes desfere um ataque ao que me é mais caro, pois todo o meu trabalho consiste, sinto-o bem, em aprender e em mostrar que uma grande poesia épica viveu e reinou na Terra, que foi gradualmente perdida e esquecida pelos homens ou até, de modo algo diferente, que continuam a alimentar-se dela" (JOLLES, 1976, p. 186).
} 
que é urgente aprender a ver em profundidade essa literatura, para que se possa fazer "um juízo mais claro das suas características, supostamente estúpidas, vulgares e até mesmo destituídas de bom gosto" (GRIMM, 2012, p. 16):

\begin{abstract}
Acima de tudo, é importante que estes itens sejam coligidos com a maior exatidão e pormenor da boca dos informadores, de modo literal e fiel, sem retoques nem acrescentos e, sempre que possível, usando as suas próprias palavras. Se o material pudesse ser obtido no dialeto respectivo, tal duplicaria o seu valor (GRIMM, 2012, p. 16).
\end{abstract}

Jacob Grimm quer evitar erros e preconceitos durante um processo que sabe ser sensível e sujeito a inúmeras vicissitudes e, por isso, recomenda, mostrando um conhecimento integral e exato do que deve ser uma recolha científica:

\begin{abstract}
Por outro lado, importa não rejeitar fragmentos incompletos, pois pode dar-se o caso de cada uma das variantes, repetições e versões de uma mesma lenda se revelarem importantes. Haverá que evitar o erro de não recolher uma determinada narrativa sob o falso pretexto de já ter sido anteriormente recolhida e coligida. Muito do que se afigura moderno é amiúde meramente modernizado e retém a sua identidade básica sob a superfície (GRIMM, 2012, p. 16).
\end{abstract}

A originalidade e a consistência do pensamento dos Irmãos Grimm são bem visíveis não só em relação aos aspectos que enumeramos, mas também numa questão menos evidente de terminologia. Jacob usa os termos "versão" e "variante" de um modo que deixa perceber que lida sem dificuldade com conceitos que hoje nem todos os estudiosos, incluindo alguns acadêmicos, controlam: as "versões" são as ocorrências de um texto-tipo e as "variantes" são as diferenças que existem entre versões do mesmo texto-tipo.

As advertências de Jacob Grimm estendem-se ainda aos lugares e aos informantes a privilegiar na prospecção, ao cuidado a ter na formalização da recolha de cada texto e à atenção a dar aos "livros em alto-alemão e manuscritos em arquivos e mosteiros" (GRIMM, 2012, p. 17):

Em geral, porém, podemos afirmar o seguinte: se não há quase nenhuma região completamente desprovida ou despojada de poesia popular, as mais ricas e férteis em folclore são as vilas de província e não tanto as grandes cidades, e, mais, ainda do que as vilas de província, são as aldeias e, das aldeias, destacam-se as mais tranquilas e isoladas, situadas em regiões de floresta ou de montanha. Além disso, o folclore tende a ficar mais fortemente arraigado entre os membros de certas profissões, como os pastores, os pescadores e os mineiros. É por isso preferível interrogar estes indivíduos, bem como pessoas idosas, mulheres e crianças, que ainda mantêm recordações vivas do folclore que lhes foi transmitido.

(...)

Finalmente, a fim de assegurar a boa preservação do material recolhido, solicitamos que colija cada item numa folha de papel individual, indicando o lugar, a comunidade e a data da recolha, bem como, se necessário, o nome do narrador a seguir ao seu nome (GRIMM, 2012, p.16-17). 
O rigor deste método não nos deve fazer esquecer uma fragilidade que lhe podemos apontar. Referimo-nos a pouca atenção que Jacob dá ao registro do nome do narrador e ao nenhum interesse que lhe despertam a idade do informante, o seu local de nascimento e outros elementos ligados ao contexto de enunciação (comentários, não necessariamente dirigidos pelo "recoletor", como a relação do informante com o conto e onde e a quem o ouviu ou onde o leu). Essa fragilidade não só persistiu durante muito tempo um pouco por todo o lado como, em muitos casos, ainda se verifica.

Por isso é que encontramos, nos Kinder- und Hausmärchen, uma oscilação curiosa: temos muitos nomes individuais e nomes de famílias da classe média, mas poucos nomes individuais de informantes do "povo". A regra, quando a fonte é "popular", consiste em indicar uma informação simples e genérica: “informador desconhecido". Parece óbvio que os autores incluíram os nomes dos seus conhecidos por cortesia, não porque lhes interesse a sua individualidade ou porque lhes quisessem atribuir destaque. Mas esta opção acaba por ser muito significativa: diz-nos que a literatura oral, ao contrário do que se afirma ou assume como incontestável, não é, nem nunca foi, exclusiva das classes ditas "populares" ou subalternas. O sucesso da recolha dos Grimm junto de famílias educadas mostra bem a profundidade da aquisição de um patrimônio de textos literários orais durante a infância. Isso porque estas pessoas em situação "bicultural” (BURKE, 2010, p.18) não esqueceram essa outra cultura, apesar da imersão na cultura letrada e erudita.

Poder-se-á argumentar que há diferenças no modo como um "iletrado" e um "letrado" convivem com tais textos, mas isso não diminui em nada a importância quer dessa literatura, quer da recolha dos Irmãos Grimm. Pelo contrário: por aqui se percebe a universalidade dos contos maravilhosos (e de outros gêneros orais), a sua transversalidade social e cultural; e por aqui se percebe como numa recolha de literatura oral não devemos ignorar determinadas classes sociais ou profissionais nem certas faixas etárias (nem as mais novas nem as intermédias).

O motivo do esquecimento ou menorização do informante, na recolha dos Grimm, está na própria concepção de poesia (de literatura) dos Irmãos Grimm, que radica na conhecida oposição entre "poesia natural" (Naturpoesie) e "poesia artística" (Kunstpoesie). Para Jacob Grimm, como nos lembra André Jolles no capítulo sobre "O Conto" do seu livro Formas Simples (1930), a "poesia natural" e a "poesia artística" são absolutamente diferentes e inconciliáveis: a primeira é espontânea e coletiva, nasce da inocência e da essência mais 
misteriosa e insondável do povo; a segunda é individual. Quer isso dizer que o indivíduo, o informante, o narrador, na "poesia natural", interessa menos do que o texto e, portanto, o seu nome, a sua idade e outros elementos biográficos são irrelevantes para quem recolhe e para a versão escrita do texto oral. Não custa chegar a essa conclusão a partir da resposta expressiva e peremptória de Jacob a Achim von Arnim, que, pelo contrário, não via “oposição alguma entre a poesia popular e a poesia erudita" (JOLLES, 1976, p.183):

A poesia é aquilo que passa em estado de pureza e sem alterações do coração para as
palavras; por conseguinte, é algo que brota incessantemente de um impulso natural e é
captado por uma faculdade inata; a poesia popular sai do coração do Todo; o que entendo por
poesia artística sai da alma individual. Por isso é que a poesia moderna assinala os seus
autores, ao passo que a antiga não sabe nome algum; ela não é produzida por um, dois ou
três, é a soma do Todo; já disse que não sei explicar como essas coisas foram arranjadas e
feitas, mas, para mim, não é mais misterioso do que as águas que confluem num rio para
correr juntas. Não seria capaz de conceber a existência de Homero nem que os
Nibelungenlied tivessem um autor (JOLLES, 1976, p. 183-184).

Como se percebe, as ideias dos Irmãos Grimm acerca do processo de recolha e, sobretudo, de edição de textos orais e tradicionais nada têm a ver com os critérios adotados por autores como o inglês Peirce, no séc. XVIII, ou os portugueses Almeida Garrett e Estácio da Veiga, no séc. XIX ${ }^{4}$. No estudo $A$ Gênese do 'Romanceiro do Algarve' de Estácio da Veiga, José Joaquim Dias Marques designa estas liberdades de "método editorial criativo" (MARQUES, 2002, p. 22). O que dissemos até aqui acerca do respeito dos Grimm pelos textos orais não nos impede, contudo, de aplicar aquela fórmula ao método por eles desenvolvido. Veremos a seguir em que termos ela se lhes ajusta.

Em 1812, Jacob Grimm aproveita um comentário de Arnim, que diz preferir os Kinder- und Hausmärchen às adaptações de Clemens von Brentano, para, mais uma vez, e com renovada acritude, censurar os exageros artificiosos da poesia moderna e fazer a apologia da poesia antiga: "Saber que a transposição de Clemens não te satisfaz deu-me grande prazer e apenas lamento o esforço e o espírito que ele lhes dedicou; por mais que embeleze e ornamente tudo isso, as narrativas simples que reunimos fielmente decerto envergonharão as dele" (JOLLES, 1976, p.185). O seu entusiasmo leva-o ainda a acrescentar:

\footnotetext{
${ }^{4}$ Para não se pensar que estamos a atribuir originalidade absoluta aos Irmãos Grimm neste capítulo dos critérios de recolha, salientamos o nome do também alemão Herder, o primeiro a estudar poesia oral na Alemanha (MARQUES, 2002, p. 36). Em 1777, cerca de quatro décadas antes dos estudos e da recolha dos Grimm, ele definia nestes termos "as condições a que, na sua opinião, deveriam obedecer essas colecções dos cantos de cada povo" (MARQUES, 2002, p. 41):
}

Essi devono trasmettere tutto com'è, nella lingua originaria e con spiegazione sobria, priva di scherno e critiche, ed anche di abbellimenti e nobilitazione, possibilmente con la loro melodia e tutto ció che appartiene alla vita del popolo (MARQUES, 2002, p. 41). 
O meu respeito pela época aumenta dia a dia; creio que não se pode inventá-la e acabarei por tornar-me parcial e não gostar de outra coisa. Eis essa nova e pura inocência, que ali está em toda a sua espontaneidade. Vós, os poetas modernos, por muito que vos esforceis, não inventais nenhuma cor nova e limitais-vos a misturá-las, que direi eu!, nem sabeis sequer aplicá-las sem mistura... (JOLLES, 1976, p. 185)

A resposta de Achim, que percebeu o alcance da crítica de Jacob, não foi menos incisiva: Jacob não é, infelizmente, capaz de entender os poetas modernos; e também não percebe que os contos de Brentano não podem ser vistos como histórias "vividas na esfera da infância e que possam, portanto, ser passadas às crianças sem qualquer preparação prévia" (JOLLES, 1976, p. 186). Não se pode esquecer que esse "é um livro que instiga em pessoas de mais idade a faculdade de invenção e mostra a todas as mães, se necessário (excetuando-se, talvez, as mulheres muito cultas), como fazer de uma circunstância, cujo atrativo elas descobriram, o divertimento duradouro de uma narrativa bastante extensa" (JOLLES, 1976, p. 186).

Insistimos nas palavras de Jacob e de Arnim, já bem destacadas por André Jolles, porque, no fundo, os Irmãos Grimm não só acabam por usar cada vez mais um "método editorial criativo" na fixação dos contos que recolheram como vêm, desse modo, a contribuir para a sua sobrevivência. Afinal, as suas versões, na linha do pensamento de Achim, estão do lado da "invenção", e são, elas próprias, um “incentivo à invenção" (JOLLES, 1976, p.186). Não estamos a afirmar que os Grimm incorreram no pecado do excesso que condenavam aos outros; mas também não estamos a ser crédulos a ponto de aceitar o conceito de fidelidade aos originais com que Jacob se defende das acusações de Arnim:

\footnotetext{
Eis-nos chegados à fidelidade. Uma fidelidade matemática é absolutamente impossível e não existe nem mesmo na história mais verdadeira e rigorosa; mas isso carece de importância, pois sentimos que a fidelidade é coisa verdadeira e não ilusão; ela opõe-se, portanto, à infidelidade. Não podes escrever uma narrativa perfeitamente fiel e conforme, assim como não podes quebrar um ovo sem que uma parte da clara adira à casca; é a consequência inevitável de todo o labor humano e é a façon que muda constantemente. Para mim, a verdadeira fidelidade, nessa imagem, seria não quebrar a gema do ovo (JOLLES, 1976, p. 187-188).
}

Perante as críticas de Arnim, Jacob é obrigado a admitir que ele e o irmão alteraram a forma, mas mantiveram o conteúdo. Para explicar com clareza e expressividade o seu ponto de vista, usa a imagem da "gema do ovo". Nos seus contos a linguagem muda, mas não há alterações de qualquer tipo ao nível das personagens, dos motivos essenciais ou das unidades narrativas: 
Se duvidas da fidelidade dos nossos Contos, não podes duvidar dessa outra fidelidade, pois ela existe. Quanto à outra e impossível fidelidade, nós próprios e outros que no-los narraram outrora, com palavras em grande parte diferentes, nem por isso fomos menos fiéis: nada de fundamental foi acrescentado ou mudado (JOLLES, 1976, p. 188).

É também sabido que "Os Grimm não ficaram indiferentes" às “críticas" de personalidades como Johann Gustav Büsching e Albert Ludwig Grimm (BAIROS, 2012, p. 17): demasiados contos de origem francesa e italiana, episódios ou motivos excessivamente crus e violentos, mau gosto estilístico de algumas passagens. Por isso, nas notas que acompanham as sucessivas edições, os autores sublinham bem a introdução de novos contos, a revisão ou reescrita de alguns e ainda a supressão de outros: "Esta quinta edição contém uma vez mais um número significativo de novos contos, enquanto outros foram trabalhados ou aumentados a partir de versões mais completas. Desde a primeira publicação desta recolha de contos que a pouco e pouco se foram acrescentando mais de cinquenta histórias" (GRIMM, 2012, p. 43).

Os argumentos daqueles que colocavam reservas ao acervo reunido pelos Grimm são conhecidos: as famílias com que os Grimm conviviam em Kassel, e nas quais recolheram uma grande parte dos contos, eram não só de origem francesa como também pertenciam à burguesia e à aristocracia cultas (ZIPES, 2006, p.81). Em muitos casos, a recolha aconteceu diretamente junto de membros dessas famílias, que haviam lido ou ouvido os contos a amas, governantas e criadas (ZIPES, 2006, p.81). Os detratores insistiram particularmente no fato de trinta e cinco textos terem sido ouvidos por uma camponesa, Dorothea Viehmann, esposa de um alfaiate, "descendente de uma família de huguenotes franceses" (BAIROS, 2012, p. 12).

A acusação de que a sua coleção não seria genuinamente alemã levou-os a assumir uma atitude mais cautelosa em relação ao contexto em que a recolha decorria e à edição dos textos. Logo na edição de 1819, lê-se:

\begin{abstract}
Era nossa intenção incorporar todo o material que até agora conseguimos reunir nesta segunda edição do livro. Por esse motivo, o primeiro volume foi quase inteiramente reescrito. Completamos o que estava incompleto, simplificamos e depuramos histórias, e serão poucos os contos que não aparecem numa versão melhorada. Tornamos a rever tudo o que parecesse suspeito - isto é, que pudesse ser de origem estrangeira ou tivesse sido distorcido por adições posteriores - e pusemo-lo de parte quando era esse o caso. Em contrapartida, inserimos novos contos, que incluem contributos da Áustria e da Boémia alemã, pelo que se encontrará aqui muita coisa até agora desconhecida (GRIMM, 2012, p. 38).
\end{abstract}

Alterações, revisões, acrescentos e supressões verificaram-se também na última edição: "Na sétima edição, acrescentou-se um conto do século XV (n. $\left.{ }^{\circ} 151\right)$, bem como três 
outros contos recolhidos por transmissão oral $\left(\mathrm{n}^{\circ}{ }^{\circ} 104, \mathrm{n}^{\circ} 175\right.$ e n. $\left.{ }^{\circ} 191\right)$ que vieram substituir dois excluídos por provirem de solo estrangeiro, tal como se demonstra na nova edição do terceiro volume" (GRIMM, 2012, p. 45).

No início, os Grimm não se preocuparam com a "nacionalidade" dos contos que iam recolhendo (ZIPES, 2006,p. 81), nem propriamente com o perfil dos informantes, que pertenciam tanto às classes ditas subalternas como às classes cultural e economicamente mais privilegiadas. Isso nos lembra, aliás, como os contos maravilhosos são indiferentes a fronteiras físicas, ideológicas ou de classes sociais. Os valores e as aspirações essenciais do conto maravilhoso e do conto popular em geral - amor e ódio, verdade e mentira, vida e morte - são comuns a todas as culturas. Entretanto, à medida que as edições dos Kinder- und Hausmärchen se iam sucedendo, e com elas as revisões cada vez mais acentuadas, os contos dos Grimm tornaram-se cada vez menos orais e cada vez mais de autor. O "fundo" permaneceu folclórico, mas a forma estilizou-se, depurou-se, perdeu as instabilidades próprias do discurso oral, sem deixar de ser, contudo, oralizante. Desapareceram as repetições de palavras, os erros ou os lapsos gramaticais e estruturais, elevou-se, de modo equilibrado, o nível de língua e o estilo. Os contos recuperaram, segundo a visão dos Grimm, o autêntico e natural estilo folclórico.

Não faltam, em cada conto, provas inequívocas das interferências dos Irmãos Grimm, em particular de Wilhelm, que, embora fiel a um estilo claro, simples e desafetado, corrige, embeleza e amplia significativamente os originais (CORTEZ, 2001, p. 28; BAIROS, 2012, p. 18). Há em vista um leitor modelo (aquele definido por Umberto Eco) e há uma matriz de perfeição que se perdeu na transmissão oral (ou não é compatível com ela) e que importa restaurar. Nesse leitor modelo entra também, a partir da segunda edição, a criança, não já apenas os leitores adultos, o que explica a supressão ou a suavização de expressões e episódios considerados mais realistas ou violentos.

Vários estudiosos têm evidenciado a dimensão das alterações realizadas pelos Irmãos Grimm nos contos que eles próprios recolheram. São muitas e às vezes muito substanciais as diferenças, sobretudo na forma, mas também no conteúdo, entre as versões publicadas em 1812, ou apenas em edições posteriores, e a última edição em vida dos Grimm (1856-1857). As comparações intertextuais entre as diversas edições dos Kinder- und Hausmärchen não deixam dúvidas em relação ao método editorial dos autores; mas a descoberta do manuscrito com quarenta e nove contos que os Grimm haviam remetido a Clemens Von Brentano em 1810 veio tornar ainda mais evidente a amplitude dessas transformações. Brentano, para quem 
Jacob e Wilhelm haviam coligido os contos, guardou o manuscrito no Mosteiro de Ölenberg, na Alsácia, onde foi redescoberto em 1920 e publicado em diferentes edições em 1924, 1927 e 1974 (ZIPES, 2006, p. 82). Os Grimm, pelo contrário, destruíram o seu manuscrito após a edição em dois volumes dos Kinder- und Hausmärchen.

Ao afirmar, na polêmica que o opôs a Jacob, que os Irmãos Grimm fizeram obra individual com os contos que recolheram, Arnim tem, em grande parte, razão. Ele defende o autor moderno que é capaz, a partir da obra antiga, construir uma obra nova, "sobretudo por meio da tradição, das coisas antigas, do fundo popular” (JOLLES, 1976, p. 186).

\begin{abstract}
Não desejaria magoar-te, mas não posso evitar fazer-te esta observação: jamais acreditarei, mesmo que tu próprio o creias, que os Kindermärchen foram transcritos tal qual os recebestes; a tendência para constituir e continuar uma obra é mais forte no homem que todos os seus projectos e simplesmente impossível de erradicar (JOLLES, 1976, p. 187).
\end{abstract}

São muito distintas as opiniões dos estudiosos relativamente às intenções que subjazem ao comportamento editorial dos Irmãos Grimm. Para Jack Zipes, que em 1983 usa o adjetivo "honorable" para caracterizar os objetivos de Jacob e Wilhelm (ZIPES, 1983, p. 61), "there is no evidence to indicate that the Grimms consciously sought to dupe German readers and feed them lies about the German past" (ZIPES,2002,p. 110). Outros acadêmicos permanecem um pouco céticos perante a defesa dos Grimm, que, segundo eles, aconteceu apenas porque houve críticas; caso contrário, eles ter-se-iam mantido silenciosos. E há ainda aqueles que não acreditam na boa fé de Jacob e Wilhelm, muito em particular John Ellis, que afirma: “(...) the Grimms deliberately, persistently, and completely misrepresented the status of their tales" e "made claims for them which they knew to be quite false" (ELLIS, 1983, p.viii).

Parece-nos que devemos ver este problema desde uma perspectiva diferente. As contradições e as hesitações que detectamos nos argumentos com que os Grimm justificam a sua recolha e o seu método de edição indiciam, antes de mais, os conflitos que a recolha e a edição de um corpus de contos tradicionais colocam a qualquer "recoletor" e, simultaneamente ou não, editor. A edição de textos em prosa coloca quase sempre problemas que não surgem tanto, como é óbvio, quando se trata de editar textos em verso, cuja maior estabilidade formal decorre do metro e da rima. Se se tem em conta o público em geral, ou mesmo um público específico como o infantil e juvenil, pode ser necessário introduzir pelo menos algumas alterações e ajustes nas versões em prosa de que se parte; ou o texto não será 
legível e apelativo, e portanto não poderá dar origem a um álbum ilustrado que tem como leitores preferenciais a criança e o jovem.

Se, como acontece nos Kinder- und Hausmärchen, se pretender chegar ao leitor infantil e juvenil, os problemas editoriais são inevitáveis. Mais importante do que procurarmos encontrar provas da nossa adesão ou condenação do método e do estilo dos Grimm é não esquecermos que as suas versões deram origem a um corpus clássico de contos maravilhosos; e que alimentaram e continuam a alimentar uma literatura infantil e juvenil que retoma, parodia e/ou subverte o cânone que eles instituíram. Adaptações mais ou menos recentes de alguns dos mais célebres contos dos Grimm, em línguas como o alemão, o francês, o inglês, o português, o espanhol ou o italiano, provam que a herança de Jacob e Wilhelm foi reclamada por escritores e leitores.

Os contos dos Irmãos Grimm assumem uma herança antiga e são eles próprios uma herança deixada às gerações vindouras. Trata-se de um legado que continuará a desafiar-nos desde a simples palavra que o designa. Também os qualificativos que o termo "conto" atrai, como "popular", “oral", "tradicional", "folclórico", "de fadas" ou "maravilhoso", são sempre insuficientes ou demasiado ambiciosos para catalogar os contos em que estivermos a pensar.

\section{REFERÊNCIAS}

BAIROS, Teresa Aica. "Introdução". In: Irmãos Grimm. Contos da Infância e do Lar. Tradução, introdução e notas de Teresa Aica Bairos. Coordenação Científica de Francisco Vaz da Silva. Vol. I. Lisboa: Temas e Debates / Círculo de Leitores, 2012, p. 9-25.

BRAGA, Teófilo. Contos Tradicionais do Povo Português. 2 vols. Porto: Livraria Universal de Magalhães \& Moniz - Editores, 1883.

BURKE, Peter. Cultura Popular na Idade Moderna. Tradução de Denise Bottmann. São Paulo: Companhia das Letras, 2010.

COELHO, Adolfo. Contos Populares Portugueses. Lisboa: P. Plantier, Editor, 1879.

CORTEZ, Maria Teresa. Os Contos de Grimm em Portugal. A Recepção dos Kinder- und Hausmärchen entre 1837 e 1910. Coimbra: MinervaCoimbra / Centro Interuniversitário de Estudos Germanísticos da Universidade de Coimbra / Universidade de Aveiro, 2001. 
ELLIS, John M. One Fairy Story Too Many: The Brothers Grimm and Their Tales. Chicago: University of Chicago Press, 1983.

GRIMM, Irmãos. Contos da Infância e do Lar. Tradução, introdução e notas de Teresa Aica Bairos. Coordenação Científica de Francisco Vaz da Silva. Vol. I. Lisboa: Temas e Debates / Círculo de Leitores, 2012.

JOLLES, André. Formas Simples. Tradução de Álvaro Cabral. São Paulo: Editora Cultrix, 1976.

MARQUES, José Joaquim Dias. A Gênese do 'Romanceiro do Algarve' de Estácio da Veiga. Tese de doutoramento em Literatura, especialidade de Literatura Oral e Tradicional, apresentada à Faculdade de Ciências Humanas e Sociais da Universidade do Algarve. Faro: Edição do Autor, 2002.

VANCONCELOS, José Leite de. Etnografia Portuguesa. Tentame de Sistematização. Vol. I. Reimpressão fac-similada da edição de 1980. Lisboa: ImprensaNacional - Casa da Moeda, 1994.

ZIPES, Jack. FairyTales and the Art of Subversion: The Classical Genre for Children and the Process of Civilization. New York: Methuen, 1983.

. The Brothers Grimm.From Enchanted Forests to the Modern World.2. ${ }^{\text {nd }}$ ed. New York: Palgrave Macmillan, 2002.

. Why Fairy Tales Stick. The Evolution and Relevance of a Genre. New York: Routledge, 2006. 